\title{
Therapeutic interventions in Australian primary care, youth mental health settings for young people with Borderline Personality Disorder or borderline traits
}

\section{Nikki O'Dwyer}

University of Canberra Faculty of Health

\section{Debra Rickwood}

University of Canberra Faculty of Health

\section{Dean Buckmaster}

University of Canberra Faculty of Health

Clare Watsford ( $\nabla$ clare.watsford@canberra.edu.au )

University of Canberra Faculty of Health

\section{Research article}

Keywords: youth mental health, borderline personality disorder, cognitive behaviour therapy, early intervention

Posted Date: August 21st, 2020

DOl: https://doi.org/10.21203/rs.3.rs-27756/v2

License: (c) (i) This work is licensed under a Creative Commons Attribution 4.0 International License. Read Full License

Version of Record: A version of this preprint was published at Borderline Personality Disorder and Emotion Dysregulation on October 1st, 2020. See the published version at https://doi.org/10.1186/s40479-020-00138-2. 


\section{Abstract}

Background This study aimed to investigate what therapeutic interventions were being applied by clinicians working with young people with a diagnosis of Borderline Personality Disorder or borderline traits in Australian primary mental health care settings. Given the current lack of evidence-based guidelines for treatment with this client population, investigating what is being implemented is needed. The study also aimed to determine whether the interventions clinicians are using are effective in reducing distress and increasing functioning for these clients.

Methods Participant data came from the national minimum data set for headspace youth mental health centers across Australia. Young people's data were included in the study if the young person was diagnosed with Borderline Personality Disorder or borderline traits during their first episode of care $(\mathrm{N}=701)$. Clinician data that indicated the type of intervention used at each client session and outcome measures routinely captured were analyzed to determine interventions used and outcomes achieved.

Results Results demonstrated that CBT was the most frequently used modality of intervention followed by supportive counselling and IPT, but that most clients received a variety of intervention types. There were no or only weak relationships between changes in outcomes and the amount of any type of intervention that was provided. No significant relationship was found with the amount of CBT a client received and changes in symptoms or functioning, despite being the most commonly employed modality.

Conclusions The study highlights the need for evidence-based treatment guidelines for early intervention in young people with borderline personality disorder traits.

\section{Background}

Like most mental disorders, Borderline Personality Disorder (BPD) is most likely to emerge during adolescence and early adulthood (Chanen, 2015). Given the significant emotional, functional and economic impact of this diagnosis (Byrne, Henagulph, Mclvor, Ramsey \& Carson, 2014), the need for evidence-based early intervention for young people is evident. With the paucity of evidence for adolescents and younger clients, understanding what clinicians currently do to intervene in young people's lives who meet the criteria for BPD is an important step to inform greater efficacy in treatment.

\section{Onset And Prevalence Of Borderline Personality Disorder}

Personality disorders are characterised by an on-going pattern of behaviour and inner experience which often becomes evident in adolescence or early adulthood, remains stable over time, and causes decreasing functioning and increasing distress (APA, 2013). One of the most commonly diagnosed personality disorders is borderline personality disorder (BPD). BPD has nine criteria according to the DSM5. These are: a poorly developed identity and unstable self-image; pervasive pattern of instability in interpersonal relationships; frantic efforts to avoid real or imagined abandonment; marked impulsivity; a feeling of emptiness; affective instability; difficulty controlling anger; transient paranoid ideation or 
dissociation; and recurrent suicidal or self-injurious behaviour. The diagnostic criteria maintain that personality disorders, including BPD, develop in childhood. The DSM-5 further explains that symptoms are most likely to manifest in adolescence and are likely to continue into adult life. To make a diagnosis in adolescence, however, a clinician is required to assess that the maladaptive personality traits have been pervasive and persistent for at least a year, and are considered unlikely to be limited to a normal developmental stage (Fonagy, Speranza, Luyten, Kaess, Hessels, \& Bohus, 2015).

Many clinicians and services are reluctant to diagnose and provide treatment for younger clients (Bateman, Gunderson, \& Mulder, 2015). This reluctance has been associated with a presumption that personality is still forming in adolescence and that there is a stigma associated with the diagnosis (Debast, Rossie, Feenstra, \& Hutsbaut, 2017). Consequently, terms like "emerging BPD", that avoid attributing a diagnosis, have become common. However, researchers have identified that diagnosis of BPD in adolescence is valid, reliable and predictive of serious distress and dysfunction over subsequent decades (Chanen, McCutcheon, Jovev, Jackson, \& McGorry, 2007). It has been argued that, since evidence shows that BPD symptoms that emerge in adolescence remain into adulthood, the diagnosis should simply be given and that a failure to do so likely results in ineffective treatment (Chanen \& McCutcheon, 2013).

Despite indications of clinician reluctance to diagnose BPD in those under 18 years, it is estimated that $1-3 \%$ of young people under 18 years would meet the criteria (Ostby et al. 2014). Within clinical populations, 33-49 percent of adolescent inpatients are believed to meet criteria for BPD, and 11-22 percent of adolescents being treated as outpatients. The prevalence rates in adolescence are considered similar to or higher than those reported for adults (Fonagy, et al 2015). Zanarini, Frankenburg and Kherna (2001) demonstrated that while patients with BPD most frequently start psychotherapy after the age of 18 years, their symptoms usually started much earlier. Of particular concern and highlighting the need for early intervention, this research, undertaken in the United States, found that 30 percent of the sample were self-harming prior to 12 years of age, with another 30 percent initiating self-harm between 13 and 17 years.

\section{Impact Of Borderline Personality Disorders}

Along with the likely onset of BPD during adolescence, the need for evidence-based early intervention is further supported by the established impact it has both on the individual and the community as a whole. Skodal, Gunderson, and McGlashan (2002) compared levels of psycho-social functioning in adult patients diagnosed with BPD with those with other personality disorders (schizotypal, avoidant and obsessive-compulsive personality disorder) and with patients with a major depression. Clients with BPD were less likely to be employed, had lower levels of education, were more likely to be disabled and had poorer interpersonal functioning compared with the patients with other personality disorders or major depression. Similarly, in a study 351 young adults aged 18 to 24 years, features of BPD predicted poorer academic achievement, social maladjustment and poorer overall functioning when compared with peers at two-year follow-up (Bagge, Nickell, Stepp, et al., 2004). The researchers hypothesised that the pervasive 
nature of BPD symptoms are the reason clients meeting this diagnostic classification struggle in meeting roles like being a partner, a student or an employee.

Of major concern is the research indicating a diagnosis of BPD impacts on life expectancy. Research in Scandinavia of 270,770 patients with recent onset mental disorders were followed up for six years or until death. It found that those with BPD had a life expectancy 15 to 20 years shorter than the general population (Nordentoft, Wahlbeck, Hallgren, et al., 2013). The higher mortality rate in people with a diagnosis of a personality disorder, including BPD, was related to suicide and increased medical issues (cardiovascular disease, metabolic conditions, and respiratory disease). For those with BPD, suicide and self-harm are particular risk factors affecting morbidity and mortality. For example, Goodman, Tomas, Temes et al. (2017) found in a sample of 104 adolescents and 290 adults with a diagnosis of BPD that 90 percent engaged in self-mutilation and 75 percent had made multiple suicide attempts. Further, clients with BPD have been shown to complete suicide 50 times high than the general population (APA, 2001).

The impact on community resources is also evident. A study conducted on over 80 clients with a diagnosis of a cluster B personality disorder, largely BPD, accessing a community mental health team was conducted in the UK (Byrne, Henagulph, Mclvor, Ramsey, \& Carson, 2014). It found that participants with a cluster $B$ personality disorder had more frequent contact with duty officers, the team psychologist, care-coordinators and the medical team. They also had significantly more presentations at emergency departments, emergency psychiatric appointments and more cancelled appointments. Patients with personality disorders also had significantly lower global functioning scores compared with the control sample of 100 clients also accessing the service.

\section{Evidence-based Interventions For Borderline Personality Disorder In Young People}

Health professionals have an ethical obligation to provide services that have an evidence base (APS, 2018). The Australian Psychological Society (APS) recommends DBT and Mentalisation-based Therapy (MBT) as the "standout" interventions for adults. It also concludes that Cognitive Analytic Therapy (CAT), Cognitive Behavioural Therapy (CBT) and Schema-focused Therapy can be therapeutically indicated for less severe BPD symptomology.

The APS review reveals a current gap in the evidence for interventions for BPD for adolescents and young people compared with the evidence for adults. It found only Level III-3 evidence (a comparative study without concurrent controls) for CAT and Level IV evidence (case series with pre test/post test outcomes) for DBT. A psycho-dynamic approach was also found to have a Level IV evidence base for adolescents (APS, 2018).

Despite the limited evidence base, MBT and DBT have been shown to have the greatest impact on suicidality and self-harm in adolescent clients seeking early intervention (Fonagy, Speranza, Luyten et al., 2015). MBT assumes that the development of BPD in adolescence is grounded in a phase-specific 
compromise in the capacity to mentalise or think about thinking that occurs during adolescence (Bateman \& Fonagy, 2009). An adaptation for adolescents (MBT-A) has been developed which incorporates monthly family sessions to the treatment regime given most adolescents sill live at home. A randomised control study was conducted on a sample of 12-17 year olds who had at least one episode of self-harm (Rossouw \& Fonagy, 2012). The 12 month intervention demonstrated a significant decrease in number of suicide attempts, self-harming behaviour and depression compared with the treatment as usual condition.

DBT has been adapted for adolescent clients (DBT-A) incorporating family sessions, reducing the length of treatment and simplifying the skills to be more developmentally appropriate (Rathus \& Miller, 2007). A review of 18 studies examining the empirical outcomes of DBT interventions with adolescents has been conducted (Macpherson, Cheavens, \& Fristad, 2013). The evidence concluded an overall positive treatment effect to address suicidality $(d=0.73)$, depression $(d=0.76)$ and BPD symptomatology $(d=$ 0.65). Additionally, Mehlum and colleagues (2014), in a randomized trial with adolescents, compared enhanced usual care with DBT. DBT was superior in reducing self-harm, severity of suicidal ideation and depression. In terms of older youth aged 18 to 25 , when compared with treatment as usual, DBT showed greater reductions in suicidality, depression, number of NSSI events, BPD criteria and psychotropic medication use (Pistorello et al., 2012). Although DBT-A is emerging as a recommended treatment for adolescents with BPD, it is not an early intervention model and requires a commitment to participate in intensive multi-modal treatment. This comprehensiveness could limit access for less severe clients indicated for early intervention.

Cognitive behavioural therapy (CBT) has a Level I evidence base for the most number of disorders in the DSM-5 (APS, 2018). For BPD in young people, however, the evidence is not strong, comprising only Level III evidence, the second lowest rating. A randomised control study of adult clients with BPD receiving traditional CBT (up to 30 sessions) compared with treatment as usual, appeared to be beneficial for symptoms of depression, anxiety and negative cognition (Davidson, Norrie, Tyrer, et al., 2006). The study found, however, that a traditional CBT approach did not decrease the number of emergency contacts, hospitalisation, self-harm or improve functioning generally. A quasi-experimental design found that an adaption of CBT, named Cognitive Analytic Therapy (CAT), resulted in the reduction in externalising psychopathology, such as intense anger outbursts and disinhibited behaviour, compared with baseline (Chanen, Jackson, McCutcheon, et al., 2009). Given the fundamental aspects of identity formation and relationship experiences for people with BPD, it has been suggested that traditional CBT approaches, focusing on specific cognitions and behaviours, fail to address the fundamental aspects of the disorder such as emotional regulation, interpersonal relationships volatility, and suicidal and self-injurious behaviours (Linehan, 1997).

It is clear that for younger populations the evidence is currently not strong regarding the best treatments for BPD, although some modalities appear promising, including DBT-A and CAT. Given the impact of this diagnosis on young people, better evidence to inform treatment decisions is much needed to reduce the impact of psychopathology, improve function and reduce risk (Chanen et al. 2007). Investigating current 
practice in early intervention services for young people at risk of BPD may inform future directions in research and guideline development.

\title{
Methodology
}

\author{
Aims \\ In the absence of clear guidelines for practice, the current study aimed to investigate the therapeutic \\ interventions being used by clinicians working in an early intervention service treating young people with \\ a diagnosis of BPD or identified traits of BPD. The study also aimed to determine whether the most \\ common interventions used by clinicians were effective in reducing psychological symptoms and \\ improving functioning for these clients. It was hypothesised that the therapeutic interventions used would \\ not be well-informed by evidence, meaning that a wide range of interventions would be employed, and \\ that CBT would be the most common treatment approach (as it has the strongest evidence base \\ generally and most clinicians are trained in this approach). Secondly, it was hypothesised that CBT would \\ not result in a significant improvement in functioning or psychological distress for clients attending an \\ early intervention service with a diagnosis of BPD.
}

\section{Participants}

Participants were young people who had attended a headspace youth mental health centre. headspace is the Australian Government's national youth mental health initiative, which since 2006 has rolled out easily accessible mental health service centres designed specifically for young people aged 12 to 25 to assist with their mental health, health and wellbeing needs (McGorry et al., 2007b). Participant data came from the headspace national minimum dataset (MDS) for the four-year period from 1 April 2013 to 31 March 2017. headspace collects a MDS for all clients accessing headspace centre services (Rickwood, Paraskakis, Quin, et al., 2018). For this time period, the national dataset comprised information on 74,804 young people who were presenting for the first time at 76 headspace centres. For the current study, only young people presenting with a primary issue of Borderline Personality Traits at intake or first assessment were selected $(N=701)$.

Participants were aged between 12 and 25 years. The mean age was 19.68 years $(S D=2.76)$. The majority were female (80.7\%), 11.1 percent were male and 2.1 percent described themselves as 'other'; data were missing for 6.0 percent. Participants came from all Australian states and territories with 44.7 percent from Victoria, 15.3 percent from New South Wales, 18.5 percent from Queensland, 13.7 percent South Australia, 5.7 percent from Western Australia, 1.0 percent from Tasmania, 1.0 percent from the Australian Capital Territory and , 0.1 percent from the Northern Territory.

\section{Procedure}

The headspace national minimum dataset is collected from each client and service provider at every occasion of service. Upon initial presentation to a centre and at each subsequent occasion of service, 
clients are given either an iPad or access to a private computer to complete an electronic survey which takes approximately 15 minutes to complete. Service providers also provide relevant information from each occasion of service in an electronic form. Data are encrypted to ensure confidentiality and stored in a national data warehouse. Clients consent for their de-identified information to be used for service evaluation and research purposes. Approval for the MDS was obtained from the Clinical and Research Board sub-committee and data usage is overseen by the Data Governance Group.

For the current study, data were extracted for clients who were presenting for their first occasion of service and only clients who received a diagnosis of a personality disorder with Borderline Traits during their treatment at headspace were included. For service provider data, only data from clinicians who provided mental health care were included, such as psychologist, psychiatrists, psychiatric registrars, social workers and mental health nurses. Data from medical visits, youth work sessions or alcohol and other drug counselling were excluded.

\section{Measures}

The following measures were extracted from the minimum dataset.

\section{Client characteristics.}

Demographics. Participants' age in years, gender, Aboriginal and/or Torres Strait Islander identity, sexual orientation and level of education were extracted. These data are self-reported by young people attending headspace.

Diagnosis of BPD or presentation with BPD traits. At each occasion of service, the service provider is asked to provider information on the young person they are seeing and the services provided. This includes determining the main presenting issues for the young person and whether they have a diagnosable mental disorder. Primary diagnosis is determined from a list of 21 subcategories following the broad classifications of the DSM-5 (American Psychiatric Association, 2013). Clinicians are also able to rate the diagnosis of the young person as Not applicable or Diagnosis not yet assessed.

\section{Service provision.}

Level of Service Engagement. The number of headspace appointments participants attended was used to measure level of engagement with mental health services.

Type of intervention. At each occasion of service clinicians are asked to assign a service type for the session they provided. Clinical interventions included: assessment, Cognitive Behavioural Therapy, behavioural intervention, supportive counselling, crisis support, psycho-education, Interpersonal Therapy, Acceptance and Commitment Therapy, Mindfulness based therapy, motivational interviewing; Narrative Therapy and Other.

\section{Outcome measures.}


Social and occupational Functioning. Service providers rate the level of functioning using the one-item Social and Occupational Functioning Assessment Scale (SOFAS) ("Psychiatry Online," 2008). It is designed to be sensitive to the current functioning of the young person rather than being based purely the individual's psychological symptoms. The SOFAS is derived from the DSM-IV Global Assessment of Functioning Scale, which has shown good internal consistency and reliability with Cronbach's alpha $=.80$ (Goldman, Skodol, \& Lave, 1992). The service provider rates a client from 1 to 100, ranging from: being unable to function and maintain minimal personal hygiene for a rating of 10 or less; 11-20 occasionally fails to maintain minimal personal hygiene; $21-30$ inability to function in almost all areas; $31-40$ major impairment in several areas such as work, school or family relations; 41-50 serious impairment in social, occupational, or school functioning; 51-60 moderate difficulty in social, occupational or school functioning; 61-70 some difficulty in social, occupational or school functioning; 71-80 no more than a slight impairment in social, occupational, or school functioning; 81-90 good functioning in all areas, occupational and socially effective; 91-100 indicating superior functioning in a wide range of activities. Change in functioning was determined by subtracting the first score upon entry to the service from the last measurement taken.

Psychological Distress. Psychological distress was measured using the Kessler - 10 (K10), which measures depressed mood, hopelessness, restlessness, fatigue, nervousness and worthlessness for the last four week period (Kessler et al., 2002). Item statements (e.g. "About how often did you feel tired out for no good reason?") were rated on a five-point response scale from 'none of the time', 'a little of the time', 'some of the time', 'most of the time' to 'all of the time'. Items are summed to provide a total score ranging from 10-50, with higher scores reflecting greater distress. A score on the K-10 of 10-15 indicates low levels of distress; 16-21 indicates moderate levels; 22-29 indicates high levels; and 30-50 indicates very high levels of distress (Crufad, 2016). The K-10 has shown excellent internal consistency and reliability with Cronbach's alpha $=.93$ (Kessler et al., 2002). Change in psychological distress was determined by subtracting the first score taken upon entry to the service from the last measurement taken.

Quality of Life. Quality of life was measured by the Life Satisfaction scale (LSS) (Seligson, Huebner, \& Valois, 2003). The LSS measures quality of life in seven different domains. Participants are asked to selfreport their sense of satisfaction for family life, friendships, romantic relationships, school/work experience, yourself, where you live and life overall. Answers are given on a scale from 0-10 with 0 being the worst level of satisfaction and 10 being the best possible. A total score was derived by averaging across the seven domains. A score of 6 or more indicates a positive level of life satisfaction (Currie, Roberts, Morgan, Smith, Setterobulte, Oddrum \& Rasmussen, 2004). Change in life satisfaction was determined by subtracting the first score from the participant's initial visit from the last measurement taken at their last session. 
Data were analysed using SPSS v23 (IBM Corp, 2015).

\section{Interventions}

Participants received between 1 and 30 sessions. Note that headspace data only collects information up until the 30 session mark. The average number of sessions was $6.22(S D=6.86)$, but was highly skewed $($ skew $=1.889, \mathrm{SE}=.092)$. There were $81 \%$ who received between $1-10$ sessions. The average number of sessions for those who received up to and including 10 sessions, excluding those who received more than 10 sessions, was $3.44(\mathrm{SD}=2.64)$, and the skew was not pronounced (skew $=.896$, $\mathrm{SE}=.103$ ).

Table 1 presents the percent of clients receiving each type of intervention at each of the first 10 sessions. This showed that three quarters of participants received an assessment at their initial session. There was another $22.6 \%$ that received a therapeutic session at visit 1, primarily CBT (9.3\%). The proportion receiving assessment dropped off sharply over time and the percentage of clients receiving therapy increased. The most common therapeutic intervention by far was CBT with $39.9 \%$ receiving this intervention by session 7. After CBT, Supportive counselling and IPT were the used most frequently used. These patterns are apparent in Figure 1.

Table 1

Session number

Percentage of Clients Receiving Each Type of Intervention at Each Session Over First 10 Sessions 


\begin{tabular}{lllllllllll} 
Intervention type & 1 & 2 & 3 & 4 & 5 & 6 & 7 & 8 & 9 & 10 \\
\hline Assessment & 74.9 & 30.8 & 21.5 & 13.8 & 9.2 & 3.7 & 3.8 & 2.3 & 5.3 & 5.0 \\
\hline CBT & 9.3 & 15.9 & 27.8 & 35.4 & 38.2 & 38 & 39.9 & 35.4 & 38.6 & 33.0 \\
\hline Behavioural & 1.6 & 2.6 & 7.8 & 6.1 & 8.3 & 5.9 & 4.4 & 9.2 & 4.4 & 7.0 \\
\hline Supportive Counselling & 4.0 & 13.5 & 10.4 & 14.2 & 9.2 & 14.4 & 15.2 & 10.0 & 10.5 & 13.0 \\
\hline Crisis & .3 & 1.4 & 0.7 & 0.8 & 1.3 & 2.1 & 2.5 & 0.8 & 1.8 & 0.0 \\
\hline Psychoeducation & 1.6 & 3.6 & 6.3 & 6.10 & 3.9 & 2.1 & 2.5 & 1.5 & 6.1 & 1.0 \\
\hline IPT & 2.7 & 3.3 & 7.8 & 7.7 & 9.6 & 8.6 & 10.8 & 10.8 & 11.4 & 11.0 \\
\hline ACT & 1.4 & 1.6 & 4.4 & 3.30 & 2.6 & 5.9 & 5.1 & 6.2 & 3.5 & 5.0 \\
\hline Mindfulness & 0.5 & 1.4 & 4.4 & 4.9 & 6.1 & 8 & 5.1 & 9.2 & 4.4 & 7.0 \\
\hline MI & 0.8 & 1.4 & 0.7 & 0.8 & 0 & 0.5 & 1.3 & 0.8 & 1.8 & 2.0 \\
\hline Narrative Therapy & 0.3 & 0.2 & 0.4 & 0.8 & 0.4 & 0.5 & 0.0 & 0.0 & 1.8 & 0.0 \\
\hline Other & 2.5 & 24.3 & 7.8 & 6.1 & 11 & 10.2 & 9.5 & 13.8 & 10.5 & 16.0
\end{tabular}

Figure 1. Percentage of clients receiving each intervention type over time (sessions 1-10). Patterns in Intervention Types used across 10 sessions.

Table 2 shows the number of sessions, up to 10 sessions, that were received for each type of intervention. The most common again was CBT, however, only two clients received 10 sessions of CBT and nine clients received nine sessions. The next most common was IPT, with one client having nine sessions of this intervention. Third most common was supportive counselling, with three clients receiving eight sessions of this type of intervention.

Table 2

Number of Clients Receiving Each Number of Sessions by Type of Intervention 
$\begin{array}{lllllllllll}\text { Intervention type } & 1 & 2 & 3 & 4 & \begin{array}{l}\text { Number of sessions } \\ \text { received }\end{array} & 6 & 7 & 8 & 9 & 10\end{array}$

5

\begin{tabular}{llllllllllll}
\hline CBT & 80 & 53 & 26 & 23 & 16 & 12 & 7 & 6 & 9 & 2 \\
\hline Behavioural & 62 & 19 & 7 & 1 & 4 & 1 & 0 & 0 & 0 & 0 \\
\hline $\begin{array}{l}\text { Supportive } \\
\text { Counselling }\end{array}$ & 73 & 33 & 13 & 9 & 6 & 5 & 5 & 3 & 0 & 0 \\
\hline Crisis & 27 & 4 & 2 & 0 & 0 & 0 & 0 & 0 & 0 & 0 \\
\hline Psychoeducation & 55 & 11 & 4 & 1 & 1 & 0 & 0 & 0 & 0 & 0 \\
\hline IPT & 37 & 6 & 7 & 6 & 3 & 2 & 5 & 3 & 1 & 0 \\
\hline ACT & 24 & 8 & 3 & 2 & 0 & 2 & 1 & 0 & 0 & 0 \\
\hline Mindfulness & 36 & 11 & 3 & 5 & 1 & 1 & 0 & 1 & 0 & 0 \\
\hline MI & 24 & 5 & 0 & 0 & 0 & 0 & 0 & 0 & 0 & 0 \\
\hline Narrative Therapy & 8 & 0 & 1 & 0 & 0 & 0 & 0 & 0 & 0 & 0 \\
\hline Other & 131 & 52 & 31 & 20 & 8 & 6 & 6 & 2 & 1 & 1
\end{tabular}

\section{Outcomes}

Table 3 shows the percentage of clients who improved, had no change or got worse on each of the change measures. The K10 change scores revealed that $60 \%$ of clients either got worse or had no change. On the SOFAS, more than half improved, but $45 \%$ had no change in scores or got worse. On the LSS measure, $68.9 \%$ of scores indicated that clients were worse or had no change in their quality of life.

Table 3

Percentage of Clients Showing by Type of Change for Each Outcome Measure 


\begin{tabular}{|c|c|c|c|}
\hline Outcome & Type of change & No Change & Improved \\
\hline & Worse & & \\
\hline K10 & 19.6 & 40.4 & 39.9 \\
\hline SOFAS & 32.3 & 12.7 & 55.0 \\
\hline LSS & 22.8 & 46.1 & 31.1 \\
\hline
\end{tabular}

Table 4 shows the association between the amount of each type of intervention and the outcomes on the change scores. This reveals that the only significant positive relationships was between ACT and K10 change ( $r=.188)$ and Other interventions and K10 change ( $r=.116)$. A negative weak relationship was found between Narrative therapy and LSS change $r=.(-.123)$. All were weak relationships.

Table 4

$$
\text { Outcome measures (change) }
$$

Pearson Correlations Between Number of Sessions for Each Intervention and Change in Outcome Measures 


\begin{tabular}{lccc} 
Intervention & K10 & SOFAS & LSS \\
\hline CBT & .029 & -.005 & -.035 \\
\hline Behavioural & .028 & .001 & .002 \\
\hline Support & .001 & -.038 & .062 \\
\hline Crisis & -.006 & .010 & -.036 \\
\hline Psych ed & .053 & .027 & .045 \\
\hline IPT & .061 & -.071 & -.066 \\
\hline ACT & $.188^{\star}$ & -.028 & -.030 \\
\hline Mindfulness & .011 & .037 & -.009 \\
\hline MI & .039 & -.001 & -.026 \\
\hline Narrative & -.021 & -.075 & $-.123^{\star}$ \\
\hline Other & $.116^{\star}$ & -.010 & -.065
\end{tabular}

Notes. $N=626$. Support $=$ Supportive Counselling. Psych ed = psycho-education .

$\star p<.05$.

\section{Discussion}

The current study investigated the therapeutic interventions utilised by clinicians working in an early intervention service, treating young people with a diagnosis of BPD and identified traits of BPD. Results revealed that, as hypothesised, CBT was the most commonly utilised modality of intervention. CBT was the clear leader in treatment type with supportive counselling and IPT being the next most commonly used. Given the lack of evidence related to traditional CBT, IPT or supportive counselling in this client population the current finding highlights a gap in appropriate mental health services. It was further expected that clinicians would not be using evidence based treatments with this population. Given the limited research for CBT with BPD in young people (APS, 2018), this hypothesis was also supported. The APS literature review does not record any evidence for supportive counselling or IPT in this population, further supporting the hypothesis.

Traditional CBT does not appear to treat the core challenges of this diagnosis including self-harming behaviours, contacts with emergency services, functioning or interpersonal effectiveness (Davidson, Norrie, Tyrer et al, 2006). It would follow that early intervention modalities should specifically target symptoms such as poor emotion regulation, identity, interpersonal effectiveness and self-injurious 
behaviour. DBT, which has strong evidence in adult populations, directly addresses these areas of dysfunction (Linehan, 1997). DBT with suicidal adolescents (DBT-A), when delivered with fidelity, requires the comprehensive implementation of treatment modes such as skills group, individual therapy, phone coaching and family sessions (Rathus \& Miller, 2007). Given the imperative that early intervention is designed to be brief, cost effective and accessible (Chanen, 2017), DBT-A, in its current comprehensive form, is less indicated for early intervention. Although DBT was not originally developed for early intervention, factors associated with the development of BPD, such as emotion dysregulation and chronic and pervasive invalidation (Linehan, 1993), are amenable to change from less comprehensive adapted DBT programs.

Less comprehensive adapted DBT programs, such as skills group-only or skills group with coaching, have produced encouraging outcomes showing the potential for using DBT for early intervention. Skills group only has proven effective for adult BPD outpatients in reducing anxiety, depression, anger and emotional instability (Soler et al., 2009). Neasciu and colleagues (2014) conducted a pilot randomized clinical trial to investigate the effectiveness of DBT skills group compared with an activities-based support group, with non-BPD clients who met the criteria for high emotion dysregulation, including having an anxiety and/ or a depressive disorder. Participants in both conditions of the study reported decreases in emotion regulation. Comparatively, those participating in the 16-week adapted DBT program, showed significantly greater and faster improvement, increases in skill usage and maintained treatment gains at follow-up. Lynch and colleagues (2003) used DBT skills group and a 30-minute phone session with an emphasis on diary card review and problem solving with older adults. Phone coaching was also provided as needed. Those receiving the skills-based program showed significant reductions in depression. Other effective adaptations include a 14-week skills group only program producing reductions in ADHD symptoms (Hirvikoski et al., 2011) and a 16-week skills group only study showing improvements in treatment resistant depression (Harley et al., 2008). Kells and colleagues (2020) 24-week DBT skills training program showed improvements in emotion dysregulation and dysfunctional coping for clients with emerging BPD. Although this study did not have a control group, it shows promise for youth clients who may yet have a fully developed severe disorder.

In a specific group based early intervention BPD program for youth, Schuppert and colleagues (2009) used an adapted 17-week skills-based group with TAU and compared it with treatment as usual without group. The two conditions did not differ significantly on measures of mood regulation and borderline symptomology. The authors suggest that this lack of differentiation could be due to the low baseline scores and that the baseline measures were taken after long summer holidays leaving little room for improvement. It is noteworthy that this program may have benefitted from a tighter focus on DBT specific skills training and the need for, in addition to the skills group, some DBT specific individual therapeutic engagement and coaching as per the functions and modes of DBT. Moreover, using a specific integrated theoretical approach may have provided consistency across treatment modes (National Health and Medical Research Council, 2012). DBT has robust theoretical underpinnings, treatment functions and modes and treatment strategies, making it readily adaptable. Although initially developed and established 
as a comprehensive multimodal treatment for Borderline Personality Disorder (Linehan, 1993), DBT has the potential to be adapted for briefer, cost-effective and accessible early intervention.

Additionally, research indicates adapted versions of traditional CBT may hold promise. A randomised controlled study of clients with personality disorders receiving CBT found that a greater emphasis of work on core beliefs was a predictor of significant improvement of personality disorder symptoms (Keefe, Webb, DeRubeis, 2016). More significant adaptations such as Cognitive Analytic therapy have some established research base and appear to be better suited to early intervention settings as it is time-limited and developed specifically with BPD symptoms in mind (Chanen \& McCutcheon, 2013).

The second hypothesis was that the use of CBT with this population would not result in significant improvement in psychological distress. Results demonstrated that the amount of CBT a client received did not correlate with a significant difference in change scores on any of the outcome measures. The results also indicated that only a very small number of clients $(n=2)$ received a full 10 sessions of CBT. Given the impact of BPD criteria (Bagge, Nickell, Stepp, Durrett, Jackson, \& Trull, 2004) this may also be indicator of poor efficacy of the treatment. Clinical interviews with French adolescents with BPD and their families have highlighted that a lack of adaptation of services to the needs of young people with BPD results in greater dropout. This research found that almost half of suicidal adolescents with BPD drop out of treatment (Desrosiers, Saint-Jean, \& Laporte, 2016).

Research also indicates that the earlier a young person presenting with BPD symptoms gets appropriate treatment, the more likely they are to have a reduction or become sub-clinical in their symptomatology in adulthood (Greenfield, Henry, Lis, et.al, 2015). It is believed that the younger the client is, the more open they will be to engaging treatment, a major indicator of treatment success. Early intervention is critical to outcomes within this client population as it is in any, and so should be informed by research designed for those settings and for the specific challenges of this diagnosis (Chanen, 2015).

\section{Limitations}

The study used data routinely collected from headspace centers across the country. As such, the information was not tailored to the aims of the study, which were fitted retrospectively. Consequently, the service types that clinicians could choose from were limited and as such the "other" option results in a proportion of clinical intervention remaining unknown. Dialectical Behaviour Therapy (DBT) (Linehan, 1997) and Schema Therapy (Young, Klosko \& Weishaar, 2006) are notable omissions given the stronger evidence base for these treatments of BPD in adult populations. It should also be noted that few participants received a full course of any type of intervention and thus conclusions related to the efficacy of a full intervention are limited. To draw stronger conclusions related to the efficacy of CBT in young people with BPD, a randomised controlled study would be needed. Nevertheless, this study represents a snapshot of the interventions currently being received by this client population in real-world clinical settings, in the absence of evidence based guidelines for this age range. 


\section{Directions For Future Research}

There has been extensive research into psychological intervention for BPD, however, this evidence largely relates to adult populations. According to the APS literature review (2018) DBT, Schema Therapy and Psychodynamic therapy all have a Level I evidence base with this diagnosis in adults. Research focusing on modalities demonstrated to be useful in adult populations should be sought with young people. Building on the initial evidence that does exist around treatments such as Cognitive Analytic Therapy (CAT) and DBT-A with young people who meet the criteria for BPD should be of priority. Further, modalities that can be meaningfully implemented in early intervention settings, for example those that are brief, cost effective and accessible, could result in better outcomes for young people meeting the criteria for BPD. The development of clear guidelines around addressing emerging symptoms of BPD has been highlighted as an area of future study (Chanen, 2017). Guidelines exist for other prominent diagnoses in early intervention such as psychosis and mood however are yet undeveloped in BPD. Targeted research with this client population is an early intervention setting is required to establish these.

\section{Conclusion}

The current study investigated what clinicians are currently doing in treatment with young people meeting the criteria for BPD accessing an early intervention service. The study highlights that a wide range of interventions are being used, most of which have no evidence base. This may reflect that this common psychiatric condition lacks clear guidelines for treatment in younger populations. Given the impact that this diagnosis has on individuals and the community, and that it is mostly likely to emerge during adolescence, a considered effort should be made to focus the research into strengthening the evidence. The development of a framework for clinicians attempting to help this vulnerable population is essential to early intervention and better outcomes.

\section{Declarations}

\section{Ethics approval and consent to participate}

The headspace national minimum dataset (MDS) reported on in the present study was collected from participants who had attended a headspace youth mental health centre during the four-year period from 1 April 2013 to 31 March 2017. Data are encrypted to ensure confidentiality and stored in a national data warehouse. Clients consent for their de-identified information to be used for service evaluation and research purposes. Approval for the MDS was obtained from the Clinical and Research Board subcommittee and data usage is overseen by the Data Governance Group.

\section{Consent for publication}

Not applicable, as the manuscript does not contain data from any individual person. 


\section{Availability of data and materials}

The data that support the findings of this study are available from headspace youth mental health centre, but restrictions apply to the availability of these data, which were used under license for the current study, and so are not publicly available.

\section{Competing interests}

The authors declare that they have no competing interests.

\section{Funding}

There was no funding attached to the prepared manuscript.

\section{Authors' contributions}

N.O'D was a major contributor in writing the manuscript and in analysing the data. D.R was the primary supervisor of the project, contributor to the study design, manuscript preparation and interpreting the results. D.B provided expertise in his knowledge of the field by writing the introduction and including clinical considerations of the study. C.W contributed to the overall interpretation of the manuscript and in editing and preparing the manuscript for publication. All authors read and approved the final manuscript. All authors have agreed both to be personally accountable for the author's own contributions and to ensure that questions related to the accuracy or integrity of any part of the work, even ones in which the author was not personally involved, are appropriately investigated, resolved, and the resolution documented in the literature.

\section{Acknowledgements}

Not applicable.

\section{References}

Ali S, Findlay C. A review of the NICE guidelines on the management of borderline personality disorder. BJMP. 2016;9:16-25.

American Psychiatric Association. Diagnostic and statistical manual of mental disorders. 5th ed. Washington, DC: Author; 2013.

American Psychological Association (APA). Practice guideline for the treatment of patients with borderline personality disorder. Am J Psychiatry. 2001;158:1-52. 
Australian Psychological Society (APS). Evidence-based psychological interventions in the treatment of mental disorder: a review of the literature. The APS. 2018. 4:1-175.

Bagge C, Nickell A, Stepp S, Durrett C, Jackson K,Trull T. Borderline personality disorder features predict negative outcomes 2 years later. J Abnorm Psychol. 2004;113:79-288.

Bateman A, Fonagy P. Randomized controlled trial of outpatient mentalization-based treatment versus structured clinical management for borderline personality disorder. AJP. 2009;166:1355-1364.

Bateman A, Gunderson J, Mulder R. Treatment of personality disorder. Lancet. 2015;385:735-743.

Byrne M, Henagulph S, Mclvor R, Ramsey J, Carson. The impact of diagnosis on service usage in an adult community mental health team. Soc Psychiatry Psychiatr Epidemiol. 2014;49:307-316.

Chabrol H, Montovany A, Chouicha K, Callahan S, Mullet E. Frequency of borderline personality disorder in a sample of French high school students. CJP. 2001;46:847-849.

Chanen A, McCutcheon L. K. Prevention and early intervention for borderline personality disorder: Current status and recent evidence, $\mathrm{Br} J$ Psychiatry, 2013;202:24-29.

Chanen A. M, Jackson H. J, McCutcheon L. K, Jovev M, Dudgeon P, Yuen H. P, Clarkson V. Early intervention for adolescents with borderline personality disorder: Quasi-experimental comparison with treatment as usual. ANZJP. 2009;43:397-408.

Chanen A, McCutcheon L, Jovev M, Jackson H, McGorry P. Prevention and early intervention for borderline personality disorder. Med J Aust. 2007;187:1326-5377.

Chanen A, Sharp, C, Hoffman P. Prevention and early intervention for borderline personality disorder: a novel public health priority. World Psychiatry. 2017;16:215-216.

Currie C, Roberts C, Morgan A, Smith R, Settertobulte W, Oddrun S, Rasmussen V. Young people's health in context: International report from the HBSC 2001/02 survey. HEPCA. 2004;4:450-460.

Davidson K, Norrie J, Tyrer P, Gumley A, Tata P, Murray P, Palmer. The effectiveness of cognitive behaviour therapy for borderline personality disorder: Results from the borderline personality disorder study of cognitive therapy (BOSCOT) trial. J Pers Disord. 2006;20:450-465.

Debast I, Rossi G, Feenstra D, Hutesbaut J. Developmental sensitive markers of personality functioning in adolescent: age specific and age neutral expressions. Personal Disord. 2017;8:162-171.

Desrosiers L, Saint-Jean M, Laporte L. Model of engagement and dropout for adolescents with borderline personality disorder. Sante Mental Que. 2016;41:267-90.

Fonagy P, Speranza M, Luyten P, Kaess M, Hessels C, Bohus M. Borderline personality disorder in adolescence: An expert research review with implications for clinical practice. Eur Child Adolesc 
Psychiatry. 2015;24:1307-1320.

Goodman M, Tomas I, Temes C, Fitzmaurice G, Aguirre B, Zanarini M. Suicide attempt and self-injurious behaviour in adolescent and adult patient with borderline personality disorder. Personal Ment Health. 2017; 11:157-163.

Greenfield B, Henry M, Lis E, Slatkoff J, Guile J, Dougherty B, Zhang X, Raz A, Arnold E, Londa D, Mishara B, Koenekoop R, Castro F. Correlates, stability and predictors of borderline personality disorder among previously suicidal youth. Eur Child Adolesc Psychiatry. 2015;24:397-406.

Harley R, Sprich S, Safren S, Jacabo M, Fava M. Adaptation of dialectical behavior therapy skills training group for treatment-resistant depression. J. Nerv. Ment. Dis. 2008;196:136-143.

Hirvikoski T, Waaler E, Alfredsson J, Pihlgren C, Holmstrom A, Johnson A, Ruck J, Wiwe C, Bothhem P, Nordstrom A. Reduced ADHD Symptoms in Adults with ADHD after Structured Skills Training Group: results from a randomized controlled trial. Behav Res Ther. 2011;49:175-185.

IBM Corp. IBM SPSS Statistics for Windows. Version 23.0. Armonk, NY: IBM Corp; 2015.

Keefe J, Webb C, DeRubeis R. In cognitive therapy for depression, early focus on maladaptive beliefs may be especially efficacious for patients with personality disorders. CCPJ. 2016;84:353-364.

Kells M, Joyce M, Flynne D, Spillane A, Hayes A. Dialectical behaviour therapy skills reconsidered: applying skills training to emotionally dysregulated individuals who do not engage in suicidal and selfharming behaviours. BPD Borderline. 2020;3:1-8.

Lawrence A, Allen J, Chanen A. A study of maladaptive schemas and borderline personality disorder in young people. Cognit Ther Re. 2011;35:30-39.

Linehan M. Cognitive Behavioral Treatment of Borderline Personality Disorder. New York: Guildford; 1993.

Lynch T, Trost W, Salsman, N, Linehan M. Dialectical behavior therapy for borderline personality disorder. Annu Rev Clin Psychol. 2007:3:181-185.

Lynch T, Morse J, Mendelson T, Robins C. Dialectical Behavior Therapy for depressed older adults: A randomised pilot study. AJGP. 2003;11: 33-45.

MacPherson H, Cheavens J, Fristad M. Dialectical behavior therapy for adolescents: Theory, treatment adaptations, and empirical outcomes. Clin Child Fam Psychol Rev. 2013;16:59-80.

Mehlum L, Tormoen A, Ramberg M, Haga E, Diep L, Laberg S, Larsson B, Stanley B, Miller A, Sund A, Groholt B. Dialectical Behavior Therapy for Adolescents with Repeated Self Harm: A Randomized Trial. JAACAP. 2014;53:1082-1091. 
Meuldijk D, McCarthy A, Bourke M, Grenyer B. The value of psychological treatment for borderline personality disorder: Systematic review and cost offset analysis of economic evaluations. PLoS ONE. 2017; doi:10.1371/journal.pone.0171592

Muehlenkamp J, Ertelt T, Miller A, Claes L. Borderline personality symptoms differentiate non-suicidal and suicidal self-injury in ethnically diverse adolescent outpatients. J Child Psychol Psychiatry. 2011;52:148155.

National Health and Medical Research Council. Clinical Practice Guideline for the Management of Borderline Personality Disorder. Melbourne: National Health and Medical Research Council; 2012.

Neasciu A, Eberle J, Kramer R, Wiessmann T, Linehan M. Dialectial Behavior Therapy Skills for Transdiagnostic Emotion Dysregulationm: A Pilot Randomozed Controlled Study. Behav Res Ther. 2014;59:40-51.

Nordentoft M, Wahlbeck K, Hallgren J, Westman J, Urban O, Alinaghizadeh H, Gissler M, Munk Laursen T. Excess mortality, causes of death and life expectancy in patients with recent onset mental disorders in Denmark, Finland and Sweden. Plos One. 2013;8:1-15.

Ostby A, Czajkowski N, Knudsen P, Ystrom E, Gjerde L, Kendler K, Orstakvik R, Reichborn-Kjennerud T. Personality disorders are important risk factors for disability pensioning. Soc Psychiatry Psychiatr Epidemiol. 2014;49:2003-2011.

Pistorello J, Fruzzetti A, MacLane C, Gallop R, Iverson K. Dialectical behavior therapy (DBT) applied to college students: A randomized clinical trial. JCCP. 2012;80:982-994.

Rathus J, Miller A. Dialectical Behavior Therapy with Suicidal Adolescents. New York: Guildford Press; 2017.

Rickwood D, Paraskakis M, Quin D, Hobbs N, Ryall V, Trethowan J, McGorry P. Australia's innovation in youth mental health care - the headspace centre model. Early Interv Psychiatry. 2018; doi:10.1111/eip. 12740

Rossouw T, Fonagy P. Mentalization-based treatment for self-harm in adolescents: A randomized controlled trial. JAACAP. 2012;51:1304-1313.

Seligson J, Huebner E,Valois R. Preliminary validation of the Brief Multidimensional Students' Life Satisfaction Scale (BMSLSS). Soc. Indic. Res. 2003;61:121 -145.

Schuppert H, Giesen-Bloo J, van Gemert T, Wiersema H, Minderaa R, Emmelkamp P, Nauta M. Effectiveness of an Emotion Regulation Group Training for Adolescents-a Randomized Controlled Pilot Study. Clin Psychol Psycho. 2009;16:467-478. 
Skodol A, Gunderson J, McGlashan T, Dych I, Stout R, Bender D. Functional impairment in patients with schizotypal, borderline, avoidant, or obsessive-compulsive personality disorder. AJP. 2002;159:276-283.

Soler J, Pascual JC, Tiana T, Cebrià A, Barrachina J, Campins MJ, Gich I, Alvarez E, Pérez V. Dialectical behaviour therapy skills training compared to standard group therapy in borderline personality disorder: a 3-month randomised controlled clinical trial. Behav Res Ther. 2009;47:353-358.

Stepp S, Pilkonis, P, Hipwell A. Stability of borderline personality disorder features in girls. J. Pers. Disord. 2010;24:460-472.

Stevenson J, Meares R. Psychotherapy with borderline patients: a preliminary cost benefit study. ANZJP. 1999;33:473-477.

Young J, Klosko J, Weishaar M. Schema therapy: A practitioner's guide. New York, NY, US: Guilford Press; 2003.

Zanarini M, Frankenburg F, Khera G. Treatment histories of borderline inpatients. Compr Psychi. 2001;42:144-150.

\section{Figures}

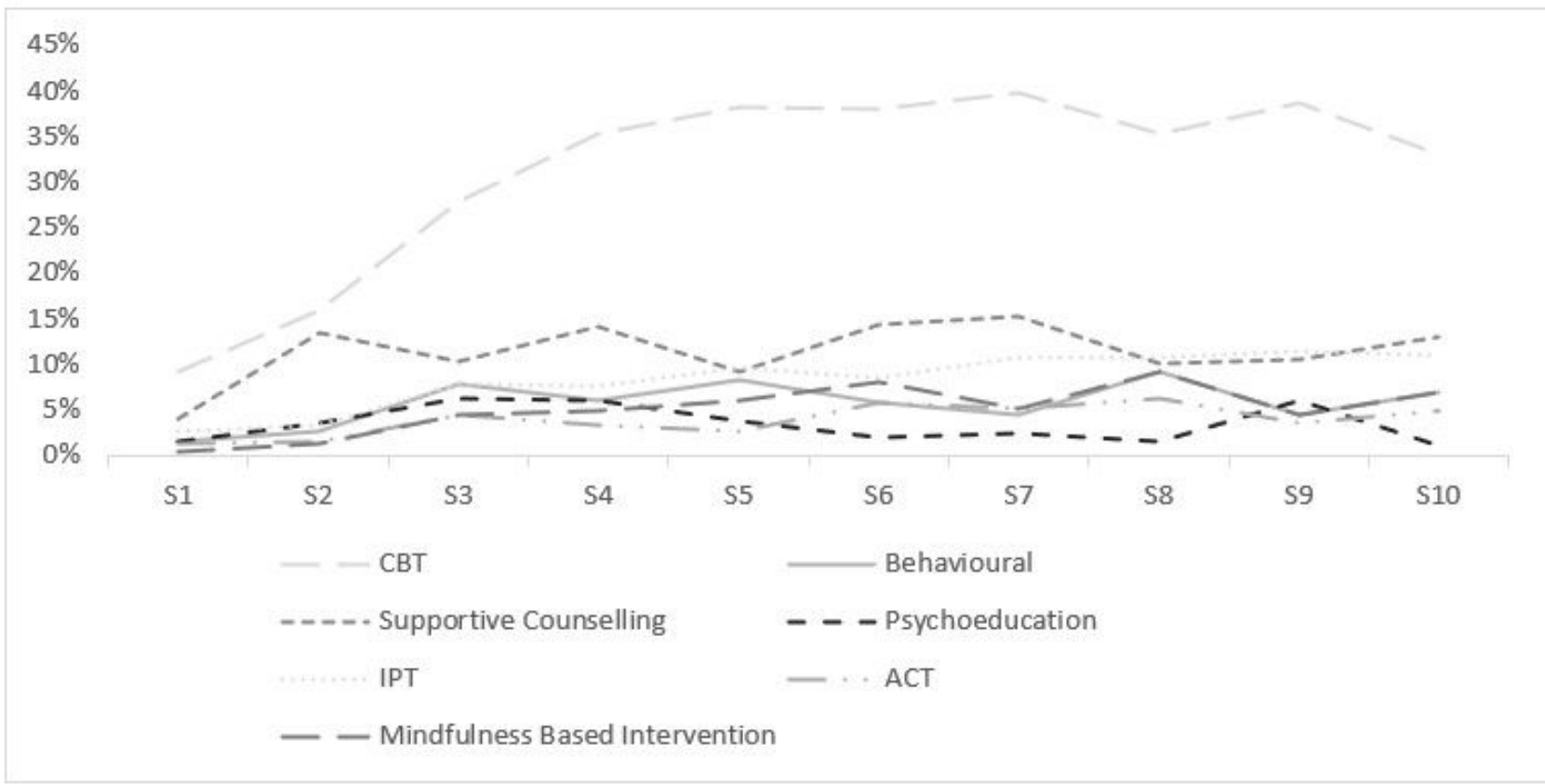

Figure 1 
Percentage of clients receiving each intervention type over time (sessions 1-10). Patterns in Intervention Types used across 10 sessions. 